\title{
ВM] Global Health Onsite midwife-led birth units (OMBUs) for care around the time of childbirth: a systematic review
}

\author{
Qian Long, ${ }^{1}$ Emma R Allanson, ${ }^{1,2}$ Jennifer Pontre, ${ }^{3}$ Özge Tunçalp, ${ }^{1}$ \\ George Justus Hofmeyr, ${ }^{4,5}$ Ahmet Metin Gülmezoglu ${ }^{1}$
}

To cite: Long $Q$,

Allanson ER, Pontre J, et al. Onsite midwife-led birth units (OMBUs) for care around the time of childbirth: a systematic review. BMJ Global Health 2016;1: e000096. doi:10.1136/ bmjgh-2016-000096

- Additional material is available. To view please visit the journal (http://dx.doi.org/ 10.1136/bmjgh-2016000096).

Received 23 May 2016

Revised 1 July 2016

Accepted 4 July 2016
CrossMark

For numbered affiliations see end of article.

Correspondence to

Dr Qian Long;

longq@who.int

\section{ABSTRACT}

Introduction: To ensure timely access to

comprehensive emergency obstetric care in low- and middle-income countries, a number of interventions have been employed. This systematic review assesses the effects of onsite midwife-led birth units (OMBUs) embedded within hospitals which provide comprehensive emergency obstetric and newborn care. Methods: Both interventional and observational studies that compared OMBUs with standard medicalled obstetric care were eligible for inclusion. Cochrane Central Register of Controlled Trials, PubMed/Medline, EMBASE, CINAHL, Science Citation and Social Sciences Citation Index, Global Health Library and one Chinese database were searched. Meta-analysis was conducted to synthesise data from randomised controlled trials (RCTs). Findings of observational studies were summarised by forest plots with brief narratives.

Results: Three RCTs, one controlled before-and-after study and six cohort studies were included. There were no or very few maternal and perinatal deaths in either OMBUs or standard obstetric units, with no significant differences between the two. Women giving birth in OMBUs were less likely to use epidural analgesia (risk ratio (RR) $0.67,95 \% \mathrm{Cl} 0.55$ to 0.82 ; three trials, $\mathrm{n}=2431$ ). The UK national cohort study and two other cohorts in China and Nepal found less oxytocin augmentation, more spontaneous vaginal deliveries, fewer caesarean sections and fewer episiotomies performed in OMBUs than in standard obstetric units. These differences were not statistically significant in RCTs and the remaining cohorts. One study investigated satisfaction with midwife-led birth care among women and midwives, with positive findings in both groups favouring OMBUs. In addition, two studies found that the total cost of birth was lower in OMBUs than in standard obstetric units. Conclusions: OMBUs could be an alternative model for providing safe and cost-effective childbirth care, which may be particularly important in low- and middleincome countries to meet the growing demand for facility-based birth for low-risk women and improve efficiency of health systems.

\section{BACKGROUND}

Globally, facility-based childbirth has been identified as a key strategy to improve the safety of intrapartum care, particularly in

\section{Key questions}

What is already known about this topic?

- Globally, facility-based childbirth has been identified as a key strategy to improve the safety of intrapartum care, particularly in low- and middle-income countries. Although progress has been made in many low- and middle-income countries, poorly staffed and equipped primary health facilities and non-functional referral systems have been recognised as constraints to improving maternal and newborn health outcomes.

- In response to potential efficiency and safety concerns of stand-alone low-risk units, onsite midwife-led birth units (OMBUs) that are adjacent to higher level care obstetric units have been introduced in some countries.

\section{What are the new findings?}

- This systematic review synthesised available evidence from interventional and observational studies and concluded that OMBUs could be an alternative model for providing safe and costeffective childbirth care, which may provide important benefits, particularly in settings where referral systems do not function well and access to care in a timely fashion is challenging.

\section{Recommendations for policy}

- Being adjacent to the obstetric unit for managing complications occurring in the intrapartum period is particularly important in many lowand middle-income countries where large numbers of maternal and neonatal deaths occur in health facilities because of failure to detect complications or lack of timely transfer of a woman to a facility with comprehensive emergency care.

- In the introduction of OMBUs, targeted pro-poor interventions should be developed to ensure equality in accessing such care.

low- and middle-income countries. ${ }^{1}$ This is critical, given that over two-thirds of maternal deaths and nearly one-third of stillbirths and neonatal deaths globally occur around the 
time of childbirth. ${ }^{2}{ }^{3}$ In many settings in the world, primary health facilities provide essential obstetric care, and pregnancies that require or develop the need for higher level care are referred to facilities that can provide comprehensive emergency obstetric care.

Although progress has been made in many low- and middle-income countries, poorly staffed and equipped primary health facilities and non-functional referral systems have been recognised as constraints to improving maternal and newborn health outcomes. ${ }^{4}$

Correspondingly, a number of interventions, such as maternity waiting facilities, emergency transfer services and targeted financial incentives at organisation and household level have been used to ensure timely access to comprehensive emergency obstetric care. ${ }^{6-8}$ While the use of facility-based care is increasing, it has followed that, in many settings, women bypass primary health facilities and instead self-refer to higher level facilities, because of the perception that doing so will provide them with a better quality of care. ${ }^{9}{ }^{10}$ It has therefore been argued that shifting birth care from the primary care setting to the higher level facilities where women are presenting may improve both health outcomes for mothers and neonates and maternal satisfaction with health services. ${ }^{9} 1112$ Conversely, a rising concern is that such a shift may result in an unreasonable burden of work on facilities, and result in unnecessarily medicalised and expensive care for low-risk pregnant women and their newborn. ${ }^{1013} 14$

Midwives are the major providers of care in childbirth, and midwifery services are underpinned by the concept of normality of childbirth in most countries. Midwife-led continuous care has been recommended for low-risk pregnant women and is considered cost-effective. ${ }^{15}$ Around $20 \%$ of low-risk pregnancies have intrapartum complications, such as fetal distress, prolonged first and/or second stage, shoulder dystocia, postpartum haemorrhage and neonatal complications. ${ }^{16}$ In response to potential efficiency and safety concerns of stand-alone low-risk units, in-hospital midwife-led birth units that are adjacent to higher level care obstetric units have been introduced in some countries. This arrangement may provide important benefits, particularly in settings where referral systems do not function well and access to care in a timely fashion is challenging.

We therefore sought to synthesise available evidence from interventional and observational studies to assess the effects of onsite midwife-led birth units (OMBUs) around the time of childbirth on maternal and newborn health outcomes and on the provision of obstetric interventions, compared with standard obstetric units. This review also aimed to explore maternal and midwife satisfaction with onsite midwife-led birth care and gather data on the cost of care. For the purposes of this review, OMBU is defined as a midwife-led unit embedded within a hospital which provides comprehensive emergency obstetric and newborn care. An OMBU may be in a physically separate structure adjacent to the main facility or situated within the facility but independent and midwife-led until the point of up-referral.

\section{METHODS}

We conducted a systematic review following the review protocol registered in International Prospective Register of Systematic Reviews (PROSPERO) (registration number: CRD42015026043).

\section{Criteria for considering studies for this review}

Randomised, cluster randomised or non-randomised controlled trials (RCTs), controlled before-and-after studies (CBAs), cohort and interrupted time series studies, and mixed quantitative and qualitative method studies published in any language between January 1990 and August 2015 were assessed. Eligible studies included those in which the participants were pregnant women of any parity presenting at the onset of spontaneous labour intending to give birth in an OMBU, and where the comparison was care in the standard obstetric unit.

Outcomes considered were presented within the headings shown in box 1 .

\section{Search strategy}

We searched the following register and databases in August 2015 with no language restrictions: Cochrane Central Register of Controlled Trials, PubMed/Medline, EMBASE, CINAHL, Science Citation Index and Social Sciences Citation Index, Global Health Library and one Chinese database (CNKI). The electronic search strategy for

\section{Box 1}

1. Maternal and neonatal outcomes

Women

1.1. Maternal death

1.2. Severe maternal morbidity (defined by study authors in identified studies)

1.3. Postpartum haemorrhage

1.4. Admission to maternal intensive care unit

1.5. Duration of postnatal hospital stay

Babies

1.6. Perinatal mortality (stillbirth and/or neonatal deaths)

1.7. Low Apgar score ( $<7$ at $5 \mathrm{~min}$ )

1.8. Neonatal convulsions or encephalopathy

1.9. Admission to neonatal intensive care unit

2. Obstetric interventions

2.1 Epidural anaesthesia

2.2 Oxytocin augmentation

2.3 Mode of delivery (spontaneous vaginal delivery as defined by authors in identified studies, instrumental vaginal birth by forceps/vacuum and caesarean section (CS))

2.4 Episiotomy

3. Satisfaction of mothers and midwives with onsite midwife-led birth care (as described or defined by authors in identified studies)

4. Cost of giving birth in an OMBU and indicators used for costeffectiveness analysis in identified studies 
PubMed/Medline is presented in online supplementary appendix 1. In addition, we screened the reference lists of all eligible studies and contacted authors of included studies for other potentially relevant studies.

\section{Screening and data extraction}

After removing duplicates, three authors independently examined titles and then abstracts of all studies identified according to the search strategy. Full texts of relevant abstracts were retrieved for further assessment. Uncertainties were resolved through discussion with the fourth author. QL extracted data on to a single form, and data extraction was verified by ERA and JP. Extracted information included characteristics of included studies, details for quality assessment of included studies, and data on considered outcomes.

\section{Quality assessment of included studies}

Methodological quality and transparent reporting of RCTs and CBAs were assessed based on suggested risk of bias criteria for studies with a separate control group by the Cochrane Effective Practice and Organisation of Care group (EPOC). ${ }^{17}$

For cohort studies, the Newcastle-Ottawa Scale (NOS) was used for quality assessment. The NOS is recommended by the Cochrane Collaboration, ${ }^{18}$ but there have been criticisms of some aspects of this scale. ${ }^{19}{ }^{20}$ As such, and as has been done previously, ${ }^{21}$ we also included two elements from the Strengthening the Reporting of Observational Studies in Epidemiology (STROBE) quality assessment tool when assessing cohort studies. ${ }^{22}$ The combined components used to assess risk of bias of cohort studies were: (1) representativeness; (2) selection of the controls; (3) ascertainment of exposure; (4) outcomes not present at the start; (5) comparability for parity (as parity was considered significant in controlling for potential outcomes of intrapartum management); (6) assessment of outcome; (7) follow-up duration; (8) adequate follow-up; (9) all outcome measures reported; (10) sources of bias discussed. Three authors (QL, ERA and JP) judged each component of the assessment tools to be of 'low', 'high' and 'unclear' risk. The discrepancy was solved through discussion with the fourth author (OT).

\section{Data analysis}

Studies were grouped on the basis of study design. We conducted meta-analysis for combining data in the RCTs. We considered an $\mathrm{I}^{2}$ value of $>50 \%$ as suggestive of substantial heterogeneity. If significant heterogeneity was identified, a pooled effect was estimated using a random-effects model taking into account variance within and between studies. Otherwise, a fixed-effects analysis was used if trials were sufficiently similar. Given substantial heterogeneity across observational studies, we calculated unadjusted risk ratios (RRs) with 95\% CI for considered outcomes in each observational study where data were available rather than pooled effect estimates. We also investigated a potential source of heterogeneity across studies by stratification of nulliparous and multiparous women. All quantitative analyses were performed using Review Manager V.5.3 (Revman; The Cochrane Collaboration, Oxford, UK). In addition, owing to the lack of consistency in the measurements, we summarised findings on maternal and midwife satisfaction with midwife-led birth care and economic evaluation of care as brief narratives.

\section{RESULTS \\ Description of studies}

The electronic search strategy yielded a total of 1494 citations, with an additional four records identified through screening reference lists and contacting authors (figure 1). Sixty-four studies were identified as potentially relevant and retrieved for full-text evaluation. Fifty studies were excluded because they reported non-OMBU interventions $(\mathrm{n}=22)$, initiated care during the antepartum period rather than at the onset of labour $(n=23)$, provided no relevant data $(n=4)$, or were duplicate publications of a study already included $(n=1)$. In total, 14 citations from 10 studies were included, with all available as English language publications.

Table 1 provides descriptions of included studies. ${ }^{23-36}$ Six of the 10 included studies were conducted in highincome countries, three in middle-income countries, and one in a low-income country, with a spread across five continents. ${ }^{37}$ The study designs included RCT $(n=3)$, CBA $(n=1)$, and six cohort studies (prospective, 3; retrospective, 3). Studies were national $(n=1)$ or conducted in a university or tertiary hospital $(n=6)$, a district or secondary hospital $(n=3)$. All studies recruited low-risk pregnant women, as defined by the study authors, and compared maternal and newborn health outcomes and intrapartum care in OMBUs with standard obstetric units. Two of the seven observational studies adjusted maternal social characteristics for the comparison, while there was no information on maternal demographic and/or socioeconomic characteristics available or no adjusted analysis performed in the remaining five studies. One study investigated satisfaction of women giving birth in an OMBU and perceptions of midwives working in an OMBU using mixed quantitative and qualitative methods; two studies investigated medical costs in OMBUs and conducted costeffectiveness analyses.

Table 2 presents the risk of bias assessment in all included studies. In summary, two of the three RCTs were assessed as being at low risk of bias, ${ }^{24} 25$ and one study did not report sequence generation and was assessed as having a high risk without adequate follow-up ${ }^{23}$ (figure 2). One CBA did not report baseline characteristics and was assessed as having a high risk without adequate sequence generation and concealment of allocation. ${ }^{27}$ For six cohort studies, half of the studies were assessed as having a high risk either without comparability by parity ${ }^{28} 29$ or without discussion of sources of bias in the study ${ }^{28} 3031$ (figure 3). 

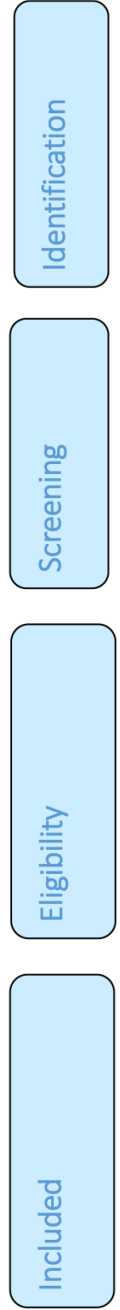

Records identified through database searching ( $n=1494$ )
Additional records identified through other sources $(n=4)$
Full-text articles excluded, with reasons $(n=50)$

- Non-OMBU intervention $(n=22)$

- Initiation of care during antenatal partum $(n=23)$

qualitative synthesis ( $n=10$ from 14 citations)

Studies included in quantitative synthesis (meta-analysis) $(n=3)$

Figure 1 Identification of studies. OMBU, onsite midwife-led birth unit.

\section{Outcome measures}

All included studies compared effects for childbearing women and their infants in the OMBU with those in the standard obstetric unit. Results are presented as outcomes relevant to maternal and neonatal health outcomes followed by obstetric interventions, satisfaction among women and midwives, and cost-effectiveness.

\section{Maternal and neonatal outcomes}

Five studies compared maternal mortality and rate of postpartum haemorrhage between OMBUs and standard obstetric units, while none of the included studies reported severe maternal morbidity, admission to maternal intensive care units or duration of postnatal hospital stay. The CBA in South Africa reported a decrease in maternal deaths following the introduction of the OMBU, ${ }^{27}$ and one cohort study in China found no maternal deaths in either group. ${ }^{33}$ Two RCTs reported a lower risk of postpartum haemorrhage in the OMBU arm compared with the standard obstetric unit (RR $0.75,95 \%$ CI 0.57 to 0.99 ; two trials, $\mathrm{n}=2161),{ }^{24} 25$ whereas one cohort study found a higher risk in the
OMBU than in the standard obstetric unit (RR 1.70, $95 \%$ CI 0.62 to 4.69 ), but the difference was not statistically significant. $^{31}$

All studies compared a variety of neonatal outcomes between the OMBU and the standard obstetric unit. Four cohort studies (including the UK national cohort) 28293335 reported no or very few stillbirths, neonatal deaths and perinatal deaths in either group. The CBA in South Africa reported a decrease in perinatal deaths following the introduction of the OMBU. ${ }^{27}$ Apgar score $<7$ at $5 \mathrm{~min}$ was measured in seven studies (three RCTs and four cohorts), and no significant difference was found between the two groups according to the pooled analyses of RCTs (RR $0.97,95 \%$ CI 0.35 to 2.71; three trials, $\mathrm{n}=2648)^{23-25}$ or each cohort study. $^{30} \quad 3133 \quad 35$ In addition, the UK national cohort study also showed no significant difference in intrapartum-related neonatal morbidities between the two groups. ${ }^{35}$ In the Norwegian RCT, there was no significant difference in the rate of transfer to the neonatal intensive care unit between giving birth in the OMBU or the obstetric unit. $^{25}$ The Nepalese cohort study found a 


\begin{tabular}{|c|c|c|c|c|c|c|c|c|c|c|}
\hline $\begin{array}{l}\text { Study } \\
\text { No }\end{array}$ & Reference & Country & Setting & Study design & $\begin{array}{l}\text { Study } \\
\text { period }\end{array}$ & Participants & $\begin{array}{l}\text { Number of } \\
\text { participants }\end{array}$ & Intervention & $\begin{array}{l}\text { Comparison } \\
\text { groups }\end{array}$ & Outcomes \\
\hline \multicolumn{11}{|l|}{$R C T$} \\
\hline 1 & $\begin{array}{l}\text { Chambliss } \\
\text { et } a^{R^{3}}\end{array}$ & USA & $\begin{array}{l}\text { One } \\
\text { university } \\
\text { hospital }\end{array}$ & $\mathrm{RCT}$ & Unknown & $\begin{array}{l}\text { Low-risk } \\
\text { pregnancy }\end{array}$ & $\begin{array}{l}\text { Total: } 487 \\
\text { P0: } 116 \\
\text { P+: } 371\end{array}$ & $\begin{array}{l}\text { Birth centre } \\
\text { managed by } \\
\text { nurse-midwives }\end{array}$ & $\begin{array}{l}\text { Delivery unit } \\
\text { managed by } \\
\text { physicians }\end{array}$ & $\begin{array}{l}\text { Mode of delivery } \\
\text { Length of labour } \\
\text { Apgar scores } \\
\text { Birth weight } \\
\text { - Use of episiotomy }\end{array}$ \\
\hline 2 & $\begin{array}{l}\text { Law and } \\
\operatorname{Lam}^{24}\end{array}$ & $\begin{array}{l}\text { Hong } \\
\text { Kong, } \\
\text { China }\end{array}$ & $\begin{array}{l}\text { One } \\
\text { tertiary } \\
\text { hospital }\end{array}$ & $\mathrm{RCT}$ & $\begin{array}{l}\text { November } \\
1994-J u n e \\
1995\end{array}$ & $\begin{array}{l}\text { Risks } \\
\text { manageable } \\
\text { by midwives }\end{array}$ & $\begin{array}{l}\text { Total: } 1050 \\
\text { P0: } 532 \\
\text { P+: } 518\end{array}$ & $\begin{array}{l}\text { Midwife-managed } \\
\text { birth care }\end{array}$ & Standard care & $\begin{array}{l}\text { Events during } \\
\text { labour } \\
\text { - Modes of delivery } \\
\text { Neonatal outcomes }\end{array}$ \\
\hline 3 & $\begin{array}{l}\text { Bernitz } \\
\text { et } a \text { R }^{526}\end{array}$ & Norway & $\begin{array}{l}\text { One } \\
\text { secondary } \\
\text { hospital }\end{array}$ & $\mathrm{RCT}$ & 2006-2010 & $\begin{array}{l}\text { Low-risk } \\
\text { pregnancy }\end{array}$ & $\begin{array}{l}\text { Total: } 1111 \\
\text { P0: } 747 \\
\text { P+: } 364\end{array}$ & Midwife-led unit & $\begin{array}{l}\text { Standard obstetric } \\
\text { unit (combined } \\
\text { normal and } \\
\text { special units) }\end{array}$ & $\begin{array}{l}\text { Operative delivery } \\
\text { rate } \\
\text { Maternal and } \\
\text { neonatal outcome } \\
\text { - Cost per patient } \\
\text { - Cost-effectiveness }\end{array}$ \\
\hline \multicolumn{11}{|l|}{$C B A$} \\
\hline 4 & $\begin{array}{l}\text { Hofmeyr } \\
\text { et } a \text { P }^{7}\end{array}$ & $\begin{array}{l}\text { South } \\
\text { Africa }\end{array}$ & $\begin{array}{l}\text { One } \\
\text { tertiary } \\
\text { hospital }\end{array}$ & CBA & 2011-2013 & $\begin{array}{l}\text { Women } \\
\text { giving birth in } \\
\text { the hospital* }\end{array}$ & $\begin{array}{l}\text { Total: } 13727 \\
\text { P0: } \\
\text { Unknown } \\
\text { P+: } \\
\text { Unknown }\end{array}$ & $\begin{array}{l}\text { Midwife-led birth } \\
\text { unit }\end{array}$ & $\begin{array}{l}\text { Obstetric unit; } \\
\text { Before and } \\
\text { after } \\
\text { intervention }\end{array}$ & $\begin{array}{l}\text { - Caesarean section } \\
\text { rate } \\
\text { - Maternal mortality } \\
\text { - Perinatal mortality }\end{array}$ \\
\hline \multicolumn{11}{|l|}{ Cohort } \\
\hline 5 & Homer et $a^{28}$ & Australia & $\begin{array}{l}\text { One } \\
\text { tertiary } \\
\text { hospital }\end{array}$ & $\begin{array}{l}\text { Retrospective } \\
\text { cohort }\end{array}$ & 1995 & $\begin{array}{l}\text { Low-risk } \\
\text { pregnancy† }\end{array}$ & $\begin{array}{l}\text { Total: } 734 \\
\text { P0: } \\
\text { Unknown } \\
\text { P+: } \\
\text { Unknown }\end{array}$ & $\begin{array}{l}\text { Birth centre } \\
\text { managed by } \\
\text { midwife }\end{array}$ & Labour ward & $\begin{array}{l}\text { Mode of delivery } \\
\text { - Analgesia in labour } \\
\text { - Perineal outcomes } \\
\text { - Neonatal outcomes }\end{array}$ \\
\hline 6 & Rana et $a^{\text {p9 }}$ & Nepal & $\begin{array}{l}\text { One district } \\
\text { hospital }\end{array}$ & $\begin{array}{l}\text { Prospective } \\
\text { cohort }\end{array}$ & $\begin{array}{l}\text { November } \\
1997- \\
\text { February } \\
1998\end{array}$ & $\begin{array}{l}\text { Low-risk } \\
\text { pregnancy }\end{array}$ & $\begin{array}{l}\text { Total: } 988 \\
\text { P0: } \\
\text { Unknown } \\
\text { P+: } \\
\text { Unknown }\end{array}$ & Midwifery unit & Consultant-led unit & $\begin{array}{l}\text { Intrapartum } \\
\text { complications and } \\
\text { procedure } \\
\text { Mode of delivery } \\
\text { - Perinatal outcomes }\end{array}$ \\
\hline 7 & Eide et $a{ }^{\beta 0} \S$ & Norway & $\begin{array}{l}\text { One } \\
\text { university } \\
\text { hospital }\end{array}$ & $\begin{array}{l}\text { Prospective } \\
\text { cohort }\end{array}$ & $\begin{array}{l}\text { November } \\
2001-M a y \\
2002\end{array}$ & $\begin{array}{l}\text { Low-risk } \\
\text { primiparous } \\
\text { womenף }\end{array}$ & Total: 453 & Midwife-led ward & $\begin{array}{l}\text { Conventional } \\
\text { delivery ward }\end{array}$ & $\begin{array}{l}\text { Intrapartum } \\
\text { interventions } \\
\text { - Neonatal outcomes }\end{array}$ \\
\hline
\end{tabular}




\begin{tabular}{|c|c|c|c|c|c|c|c|c|c|c|}
\hline $\begin{array}{l}\text { Study } \\
\text { No }\end{array}$ & Reference & Country & Setting & Study design & $\begin{array}{l}\text { Study } \\
\text { period }\end{array}$ & Participants & $\begin{array}{l}\text { Number of } \\
\text { participants }\end{array}$ & Intervention & $\begin{array}{l}\text { Comparison } \\
\text { groups }\end{array}$ & Outcomes \\
\hline 8 & $\begin{array}{l}\text { Suzuki } \\
\text { et } a{ }^{\beta 1} ; \\
\text { Suzuki }^{32}\end{array}$ & Japan & $\begin{array}{l}\text { Maternity } \\
\text { hospital }\end{array}$ & $\begin{array}{l}\text { Retrospective } \\
\text { cohort }\end{array}$ & 2008-2010 & $\begin{array}{l}\text { Low-risk } \\
\text { pregnancy }^{\star *}\end{array}$ & $\begin{array}{l}\text { Total: } 1031 \\
\text { P0: } 506 \\
\text { P+: } 525\end{array}$ & Midwife-led care & $\begin{array}{l}\text { Obstetric shared } \\
\text { care }\end{array}$ & $\begin{array}{l}\text { Obstetric outcome } \\
\text { Neonatal outcome }\end{array}$ \\
\hline 9 & $\begin{array}{l}\text { Cheung } \\
\text { et } a \beta^{33}+\dagger\end{array}$ & China & $\begin{array}{l}\text { One } \\
\text { tertiary } \\
\text { hospital }\end{array}$ & $\begin{array}{l}\text { Retrospective } \\
\text { cohort }\end{array}$ & $\begin{array}{l}\text { March- } \\
\text { September } \\
2008\end{array}$ & $\begin{array}{l}\text { Low-risk } \\
\text { pregnancy } \ddagger\end{array}$ & $\begin{array}{l}\text { Total: } 452 \\
\text { P0: } 425 \\
\text { P+: } 27\end{array}$ & Midwife-led unit & $\begin{array}{l}\text { Standard labour } \\
\text { ward }\end{array}$ & $\begin{array}{l}\text { Mode of delivery } \\
\text { Augmentation of } \\
\text { labour } \\
\text { Pain management } \\
\text { Birth companion } \\
\text { - Neonatal outcomes } \\
\text { - Satisfaction of } \\
\text { women and } \\
\text { midwives }\end{array}$ \\
\hline 10 & $\begin{array}{l}\text { Brocklehurst } \\
\text { et } a \beta^{35} \S \S ; \\
\text { Schroeder } \\
\text { et } a \beta^{\beta 6}\end{array}$ & UK & Nationwide & $\begin{array}{l}\text { Prospective } \\
\text { cohort }\end{array}$ & 2008-2010 & $\begin{array}{l}\text { Low-risk } \\
\text { pregnancyๆl }\end{array}$ & $\begin{array}{l}\text { Total: } 64538 \\
\text { P0: } 28443 \\
\text { P+: } 35289\end{array}$ & $\begin{array}{l}\text { Alongside } \\
\text { midwifery unit }\end{array}$ & $\begin{array}{l}\text { Obstetric unit } \\
\text { Freestanding } \\
\text { midwifery unit } \\
\text { Home delivery }\end{array}$ & $\begin{array}{l}\text { Perinatal mortality } \\
\text { and morbidity } \\
\text { Mode of birth } \\
\text { Maternal } \\
\text { interventions } \\
\text { Costs of delivery } \\
\text { - Cost-effectiveness }\end{array}$ \\
\hline
\end{tabular}

*No information on maternal characteristics were available.

†Women were of similar age and parity in the intervention and comparison groups; no information on other maternal characteristics was available.

$\ddagger$ Women were a similar age in the intervention and comparison groups; the socioeconomic status (defined by the study authors) of the comparison group was slightly higher than that of the intervention group.

§Adjusted for maternal age, smoking, education and marital status.

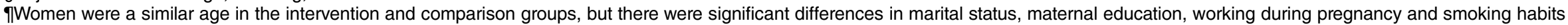
between the two groups.

${ }^{* *}$ Women were a similar age in the intervention and comparison groups; there were more primiparous women in the comparison group. No information on other maternal characteristics was available.

††Mixed quantitative and qualitative methods were used for data collection

$\ddagger \ddagger W o m e n$ were a similar age in the intervention and comparison groups; no information on other maternal characteristics was available.

$\S \S A d j u s t e d$ for maternal age, ethnic group, understanding of English, marital or partner status, body mass index in pregnancy, index of multiple deprivation score, parity and gestational age at birth

IीTThe characteristics of women in the alongside midwifery unit group were generally similar to those of the obstetric unit group.

CBA, controlled before-and-after study; $\mathrm{P} 0$, nulliparous women; $\mathrm{P}+$, multiparous women; RCT, randomised controlled trial. 
Table 2 Risk of bias assessment in included studies

EPOC criteria for randomised controlled trials and controlled before-and-after studies

\begin{tabular}{|c|c|c|c|c|c|c|c|c|c|c|c|}
\hline $\begin{array}{l}\text { Study } \\
\text { No }\end{array}$ & Reference & $\begin{array}{l}\text { Adequate } \\
\text { sequence } \\
\text { generation }\end{array}$ & $\begin{array}{l}\text { Adequate } \\
\text { concealment } \\
\text { of allocation }\end{array}$ & $\begin{array}{l}\text { Similar } \\
\text { baseline } \\
\text { outcome } \\
\text { measures }\end{array}$ & $\begin{array}{l}\text { Similar } \\
\text { baseline } \\
\text { characteristics }\end{array}$ & $\begin{array}{l}\text { Adequate } \\
\text { follow-up }\end{array}$ & $\begin{array}{l}\text { Blinding of } \\
\text { outcome } \\
\text { measures }\end{array}$ & $\begin{array}{l}\text { Adequate } \\
\text { protection } \\
\text { against } \\
\text { contamination }\end{array}$ & $\begin{array}{l}\text { Free } \\
\text { from } \\
\text { selective } \\
\text { outcome } \\
\text { reporting }\end{array}$ & $\begin{array}{l}\text { Free from } \\
\text { other } \\
\text { risks of } \\
\text { bias }\end{array}$ & - \\
\hline 1 & $\begin{array}{l}\text { Chambliss } \\
\text { et } a^{R^{3}}\end{array}$ & $?$ & + & $?$ & + & - & + & + & + & + & \\
\hline 2 & $\begin{array}{l}\text { Law and } \\
\text { Lam }^{24}\end{array}$ & + & + & $?$ & + & + & + & + & + & + & \\
\hline 3 & $\begin{array}{l}\text { Bernitz } \\
\text { et } a R^{25}, 26\end{array}$ & + & + & $?$ & + & + & + & + & + & + & \\
\hline 4 & $\begin{array}{l}\text { Hofmeyr } \\
\text { et } a^{77}\end{array}$ & - & - & $?$ & $?$ & + & + & + & + & + & \\
\hline
\end{tabular}

Newcastle-Ottawa Scale and STROBE quality assessment tool for cohort studies

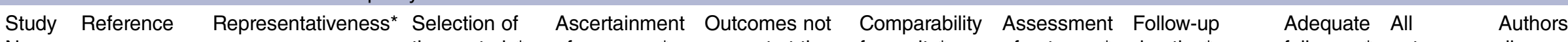

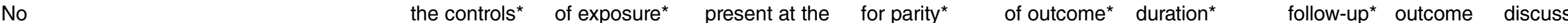
start $^{*}$ measures sources reported† of biast

\begin{tabular}{|c|c|c|c|c|c|c|c|c|c|c|c|}
\hline 5 & $\begin{array}{l}\text { Homer } \\
\text { et } a \text { f }^{8}\end{array}$ & + & + & + & + & - & + & + & + & + & - \\
\hline 6 & Rana et $a^{29}$ & + & + & + & + & - & + & + & + & + & + \\
\hline 7 & Eide et $a^{30} \ddagger$ & + & + & + & $?$ & NA & $?$ & + & + & + & - \\
\hline 8 & $\begin{array}{l}\text { Suzuki } \\
\text { et } a{ }^{\beta 1} \\
\text { Suzuki }^{32}\end{array}$ & + & + & + & + & + & + & + & + & + & - \\
\hline 9 & $\begin{array}{l}\text { Cheung } \\
\text { et }\left.a\right|^{33} 34\end{array}$ & + & + & + & - & - & - & + & + & + & + \\
\hline 10 & $\begin{array}{l}\text { Brocklehurst } \\
\text { et } a{ }^{\beta 5} ; \\
\text { Schroeder } \\
\text { et }\left.a\right|^{\beta 6}\end{array}$ & + & + & + & + & + & + & + & + & + & + \\
\hline
\end{tabular}

+ , low risk of bias; -, high risk of bias; ?, unclear risk of bias.

*Newcastle-Ottawa Scale.

†STROBE quality assessment tool.

†Eide et $\mathrm{a}^{\beta 0}$ only recruited nulliparous women.

EPOC, Effective Practice and Organisation of Care group; NA, not applicable; STROBE, Strengthening the Reporting of Observational Studies in Epidemiology. 
Figure 2 Risk of bias assessment of the three randomised controlled trials and one controlled before-and-after study.
Adequate sequence generation Adequate concealment of allocation Similar baseline outcome measures Similar baseline characteristics Adequate follow-up Blinding of outcome measures Adequate protection against contamination Free from selective outcome reporting Free from other risks of bias

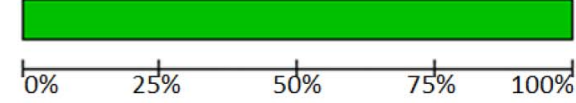

Low risk of bias Unclear risk of bias

High risk of bias significantly lower risk of infants being admitted to the special care baby unit in the OMBU group. ${ }^{29}$

\section{Obstetric interventions}

Figure 4 presents the results for comparing obstetric interventions in OMBUs with care in standard obstetric units.

Epidural anaesthesia: Six studies (three RCTs and three cohorts) compared the use of epidural anaesthesia between OMBUs and obstetric units. The pooled analyses of the RCTs showed that women giving birth in an OMBU were less likely to use epidural anaesthesia (RR $0.67,95 \%$ CI 0.55 to 0.82 ; three trials, $n=2431) .^{23-25}$ This was consistent with the findings in two cohort studies in the UK and Norway. ${ }^{30}$ A similar result was observed in an Australian cohort study (RR 0.79 , 95\% CI 0.58 to $1.09)$, but the difference was not statistically significant between the two groups ${ }^{28}$ (figure $4 \mathrm{~A}$ ).

Oxytocin augmentation: Six studies (three RCTs and three cohorts) reported oxytocin augmentation used in OMBUs and obstetric units. In the pooled analyses of the RCTs, there was no difference in oxytocin augmentation between the two groups (RR $0.98,95 \%$ CI 0.60 to 1.58; three trials, $\mathrm{n}=2334) .{ }^{23-25}$ All three cohort studies showed significantly less use of oxytocin augmentation in the OMBU 293335 (figure 4B).

Mode of delivery: All included studies investigated the mode of delivery in the OMBU and the obstetric unit. According to the pooled estimates of RCTs, ${ }^{23-25}$ there were no statistically significant differences in spontaneous vaginal deliveries (RR $1.03,95 \%$ CI 0.99 to 1.06 ; three trials, $\mathrm{n}=2648$ ), operative vaginal deliveries ( $R R$ $0.82,95 \%$ CI 0.49 to 1.37 ; three trials, $\mathrm{n}=2648$ ) or caesarean sections (CSs) (OR 1.04, 95\% CI 0.73 to 1.48 ; three trials, $n=2648$ ) between the OMBU and the standard obstetric unit. In the CBA, no CSs were performed in the OMBU compared with $45 \%$ in the standard obstetric unit. $^{27}$ The rate of $45 \%$ was slightly less than that in the standard unit in the pre-OMBU period. ${ }^{27}$ Three of the six cohort studies found that women giving birth in the OMBU were more likely to have a spontaneous vaginal delivery and were less likely to have a CS. ${ }^{29} 33 \quad 35$
Figure 3 Risk of bias assessment of the six cohort studies.

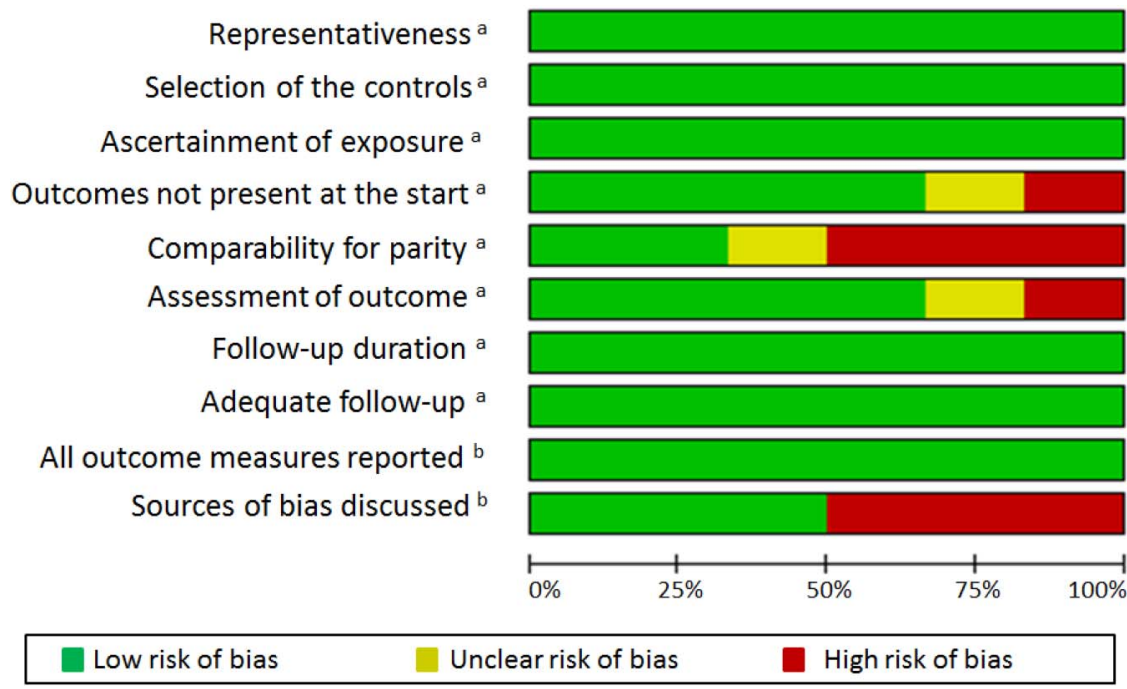

a Newcastle-Ottawa Scale; ${ }^{b}$ STROBE quality assessment tool 
A Epidural anaesthesia

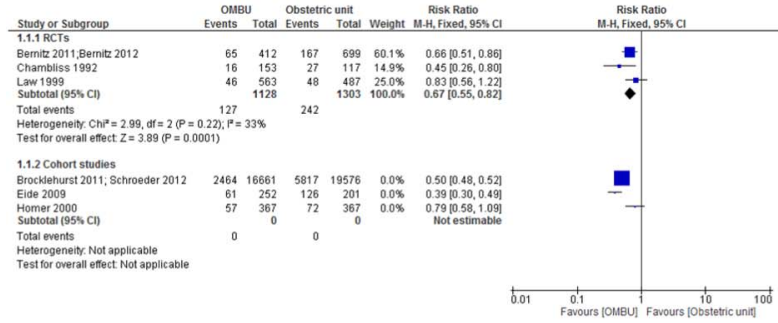

C spontaneous vaginal delivery

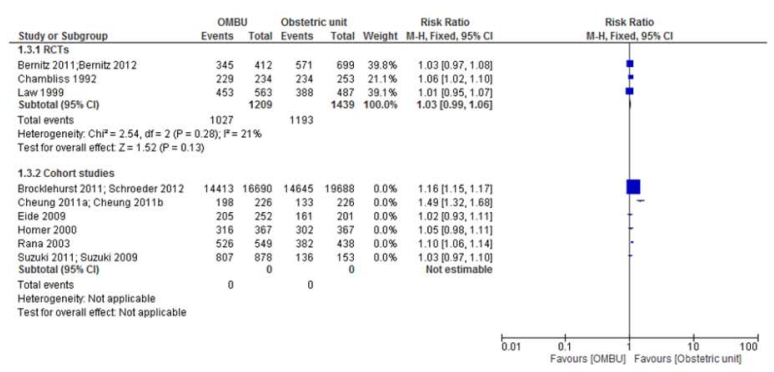

E Caesarean section

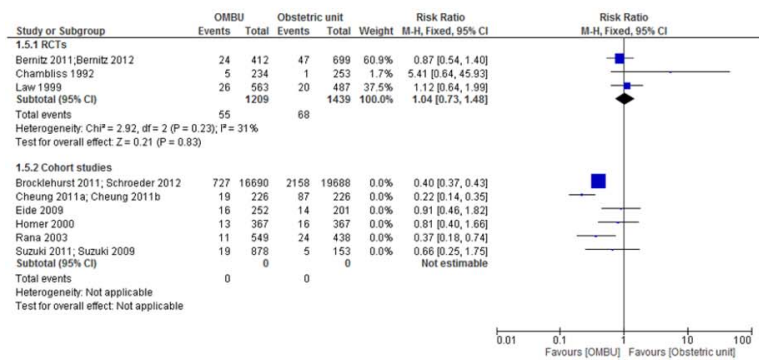

B Oxytocin augmentation

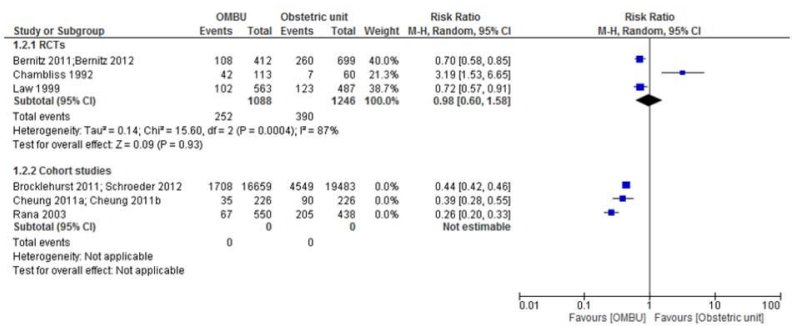

D Operative vaginal delivery

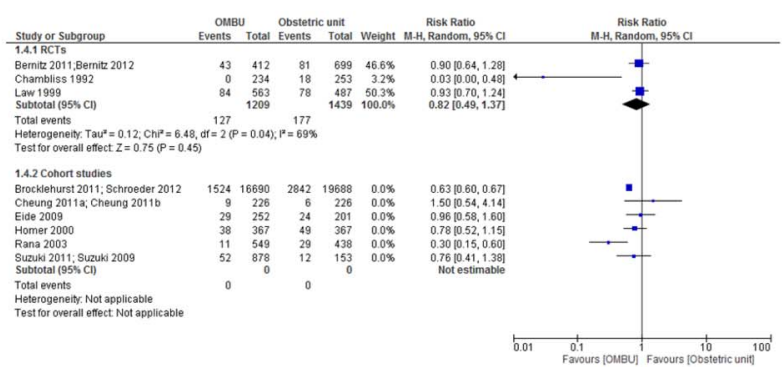

F Episiotomy

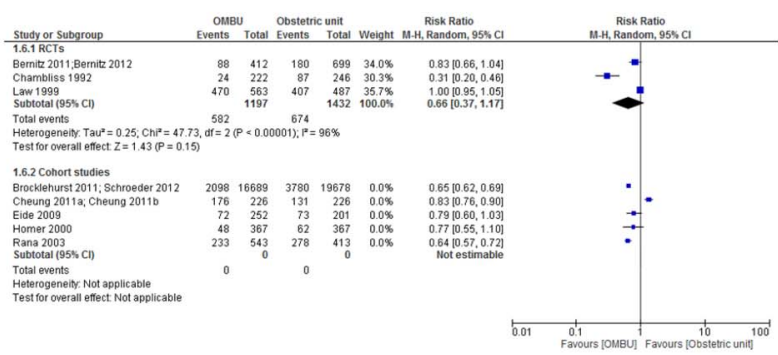

Figure 4 Quantitative analysis of comparing the obstetric interventions in an onsite midwife-led birth unit (OMBU) with care in a standard obstetric unit. (A) Epidural anaesthesia; (B) oxytocin augmentation; (C) spontaneous vaginal delivery; (D) operative vaginal delivery; (E) caesarean section; (F) episiotomy.

Although the remaining three cohorts showed similar trends, the differences in mode of delivery were not statistically significant between the two groups ${ }^{28} \quad 30 \quad 31$ (figure 4C-E).

Episiotomy: Eight studies (three RCTs and five cohorts) reported episiotomy performed in the OMBU and the obstetric unit. No statistically significant differences in episiotomy rates were found between the two groups by pooling the data from the RCTs (RR 0.66, 95\% CI 0.37 to 1.17 ; three trials, $\mathrm{n}=2629) .{ }^{23-25}$ Three of the five cohort studies showed significantly fewer episiotomies performed in the OMBU. ${ }^{29} 33 \quad 35$ The difference between the two groups in the number of episiotomies performed was not statistically significant in the remaining two cohorts ${ }^{28} 31$ (figure $4 \mathrm{~F}$ ).

The comparison of obstetric care between the OMBU and the standard obstetric unit was stratified by nulliparous and multiparous women where data were available in one RCT and three cohorts. ${ }^{25} 303135$ One RCT in Norway reported no statistically significant difference in operative vaginal deliveries and CSs by parity between the two groups. ${ }^{25}$ The UK national cohort study found significantly more spontaneous vaginal deliveries and fewer operative vaginal deliveries and CSs among nulliparous women giving birth in an OMBU. ${ }^{35}$ For multiparous women, there was no significant difference in spontaneous vaginal deliveries between the two groups, but there were significantly fewer operative vaginal deliveries and CSs in the OMBU. ${ }^{35}$ The remaining two cohort studies found no significant difference in mode of delivery by parity between the two groups. ${ }^{30} 31$

In addition, all but one study reported the rate of transfer from the OMBU to the standard obstetric unit in the case of need for higher level care, with results ranging from $6 \%$ to $42 \% .{ }^{23-25} 28-3133 \quad 35$ The UK national cohort study indicated that transfers were more common for nulliparous than multiparous women. ${ }^{35}$

\section{Satisfaction among women and midwives}

Only one study from China explored the perceptions of women and health professionals on midwife-led care through a questionnaire survey and semi-structured 
qualitative interviews. ${ }^{33} 34$ In this study, $94 \%$ of the women giving birth in the OMBU expressed satisfaction with both care received and the available birth support. All midwives who participated in the survey and qualitative interviews showed a positive attitude towards midwife-led birth care, as they were able to "play their role'. However, shortage of midwives was perceived as a barrier to the sustainability of the OMBU. It should be noted that, in this study, a birth companion model was introduced to the OMBU as part of the intervention, limiting the comparability with standard obstetric care without a birth companion.

\section{Cost-effectiveness}

Two studies presented cost-effectiveness analysis by different effect measures. ${ }^{26}{ }^{36}$ In Norway, Bernitz and colleagues estimated the total cost for each participant who was randomly assigned to either the OMBU or the standard obstetric unit in one secondary hospital from the perspective of a healthcare provider. ${ }^{26}$ Overall, total cost per stay was $€ 1672$ for women giving birth in the OMBU, compared with $€ 1950$ for women giving birth in the standard obstetric unit. In the cost-effectiveness analysis, the incremental cost-effectiveness ratio (ICER) was calculated for CS, instrumental vaginal delivery, complications requiring operative care, epidural anaesthesia, and augmentation with oxytocin. This study concluded that, for low-risk women in labour, an OMBU is a costeffective alternative. In the UK, Schroeder and colleagues estimated unit cost based on resource inputs into the components of intrapartum care and care after a stillbirth or neonatal death in the OMBU compared with the standard obstetric unit. ${ }^{36}$ The total costs were $€ 1747$ for births in the OMBU and $€ 1950$ for births in the standard obstetric unit. ICER was calculated for perinatal outcome for low-risk women in both settings. Compared with the standard obstetric unit, the OMBU was, on average, cost saving without any significant increase in adverse perinatal outcomes.

\section{DISCUSSION}

This review included three trials and seven observational studies (six cohort studies and one CBA) involving a total of 84571 women conducted in a range of high-, middle- and low-income countries. All included studies recruited low-risk pregnant women. Overall, there was no increased likelihood of any adverse maternal and newborn outcomes occurring in the OMBU compared with the standard obstetric unit. In the majority of included studies, the OMBU was associated with fewer obstetric interventions compared with the standard obstetric unit, but the difference was not statistically significant among trials. Only one study investigated satisfaction among women and midwives with midwife-led birth care, with positive findings in both groups favouring the OMBU. Although the cost-effectiveness of OMBU care was assessed using different approaches in the two studies, results generally suggested that an OMBU was a cost-saving model without increases in adverse perinatal outcomes compared with a standard obstetric unit.

A Cochrane review compared midwife-led continuous care in a variety of organisational settings with doctor-led or shared-care models through synthesis of evidence from 13 RCTs, which were all conducted in high-income countries. ${ }^{15}$ The review concluded that a midwife-led care model leads to fewer obstetric interventions, increases women's satisfaction with care, and is costeffective for low-risk pregnant women. Our review focused on the effects of midwife-led birth care in a setting with the benefit of the close comprehensive lifesaving obstetric and newborn care required in the case of complications. What is clear from this review is that, in RCTs, both maternal and neonatal outcomes were not worsened by care in an OMBU. The non-inferiority of OMBU care and the potentially improved outcomes were demonstrated in large cohort studies. From a methodological point of view, it is not clear whether the observed differences in outcomes between RCTs and observational studies are due to study design or the contextual factors associated with each of the studies. A wide range of transfer rates from OMBUs to standard obstetric units (from $6 \%$ to $40 \%$ ) highlighted the potential importance of being adjacent to the obstetric unit for managing complications occurring in the intrapartum period. This is particularly important in many low- and middle-income countries where large numbers of maternal and neonatal deaths occur in health facilities because of failure to detect complications or lack of timely transfer of a woman to a facility with comprehensive emergency care. ${ }^{38-40}$

Some strengths and limitations of this review should be acknowledged. This review used a comprehensive search strategy without language restrictions. Studies included were conducted in high-, middle- and lowincome countries, and are therefore potentially applicable to OMBU implementation in different settings. However, the number of identified randomised trials is small with relatively small sample sizes. The available evidence is instead dominated by observational studies, which do not establish causality. In addition, there was a wide variation in rates of nulliparous and multiparous women recruited in primary studies, but we were not able to address the impact of this heterogeneity on the studies because of a paucity of disaggregated data by parity. Of the observational studies included, some differences in maternal social and economic characteristics (eg, maternal education, marital status, ethnic groups) and antenatal care use were identified. Adjusted estimates were not available to control for these potential confounders in looking at the relationship between OMBU use and reported outcomes.

Facility-based childbirth that adopts a primary healthcare approach with the capacity for transfer to higher level care if necessary has been a global strategy to avoid 
preventable maternal and neonatal deaths. Furthermore, the WHO highlighted the importance of the quality of facility-based care around the time of childbirth and released the Quality of Care Framework for Maternal and Newborn Health in 2015. ${ }^{41}$ However, in many low- and middle-income countries, where $99 \%$ of global maternal and neonatal deaths occur, ${ }^{2}{ }^{3}$ primary health facilities fall far short of the necessary infrastructure and human resources to provide quality and safe intrapartum care. It is not surprising that many women self-refer to higher level care at the onset of labour because of the perception of higher quality of care in those facilities. ${ }^{9}$ The shift to hospital care has been found to be associated with an increase in unnecessary and costly obstetric interventions beyond that which would result in saving mothers and babies, taking limited health resources away from other necessary care. ${ }^{9} 13$

From the perspective of improving the efficiency of health systems, a restructuring of higher level facilities to meet the needs of low-risk pregnant women should be considered, such as the provision of OMBUs. In doing this, however, consideration should be given to potential socioeconomic inequality in accessing hospital care in many low- and middle-income countries. Should low-risk women be encouraged to attend OMBUs in higher level facilities, pro-poor interventions-for example, providing poor pregnant women with a transportation subsidy or voucher-need to be developed to improve access and use of care. In rural or remote areas where access to a health facility in geographically distant settings may be difficult, the OMBU may need to be supported by a maternity waiting facility. ${ }^{6} 42$

None of the studies included in this review assessed the impact of health system factors on the implementation of an OMBU and potential scale-up. Only one study investigated the satisfaction of mothers and midwives with onsite midwife-led birth care, and two studies, both of which were conducted in high-income settings, examined expenditure on the OMBU from a perspective of health supply. The Norway trial has recently published results on women's satisfaction with intrapartum care led by a midwife or obstetrician, and found that midwife-led birth care was more favourable. ${ }^{43}$ Generally, the lack of evidence in these areas underlines the need for further research, particularly in low- and middle-income settings, to explore these effects. In addition, to inform intervention design and implementation, assessment of accessibility and affordability of OMBU care from the perspective of women and their families will be essential.

\section{CONCLUSIONS}

Our review suggests that OMBUs could be an alternative model for providing safe and cost-effective care around the time of childbirth. This may be particular significant in low- and middle-income countries, where implementation of an OMBU may meet the growing demand for facility-based care for low-risk women and improve health system efficiency. To explore the acceptability and scale-up of the OMBU model, further research is needed to investigate factors related to OMBU implementation from the perspective of both the health system and the health system users.

\section{Author affiliations}

${ }^{1}$ Department of Reproductive Health and Research, UNDP/UNFPA/UNICEF/ WHO/World Bank Special Programme of Research, Development and Research Training in Human Reproduction (HRP), World Health Organization, Geneva, Switzerland

2Faculty of Medicine, Dentistry and Health Sciences, School of Women's and Infants' Health, University of Western Australia, Crawley, Australia

${ }^{3}$ King Edward Memorial Hospital, Subiaco, Perth, Western Australia, Australia

${ }^{4}$ Effective Care Research Unit, University of the Witwatersrand, Johannesburg, South Africa

${ }^{5}$ Walter Sisulu University and Eastern Cape Department of Health, Frere Maternity Hospital, Johannesburg, South Africa

\section{Handling editor Seye Abimbola}

Acknowledgements We would like to express our sincere appreciation to $\mathrm{Mr}$ Tomas Allen, Information Specialist at the WHO, Geneva, Switzerland for assistance in developing the search strategies.

Contributors QL, ERA, OT and AMG initiated the study concept. QL, ERA, JP and OT conducted the systematic review. QL wrote the first draft of the manuscript. EA, JP, OT, GJH and AMG participated in the interpretation of the results and contributed to writing of the manuscript.

Competing interests None declared.

Provenance and peer review Not commissioned; externally peer reviewed.

Data sharing statement No additional data are available.

Open Access This is an Open Access article distributed in accordance with the Creative Commons Attribution Non Commercial (CC BY-NC 4.0) license, which permits others to distribute, remix, adapt, build upon this work noncommercially, and license their derivative works on different terms, provided the original work is properly cited and the use is non-commercial. See: http:// creativecommons.org/licenses/by-nc/4.0/

\section{REFERENCES}

1. World Health Organization. The World Health Report 2005: make every mother and child count. Geneva: World Health Organization, 2005.

2. Say L, Chou D, Gemmill A, et al. Global causes of maternal death: a WHO systematic analysis. Lancet Glob Health 2014;2:e323-33.

3. Bhutta ZA, Das JK, Bahl R, et al. Can available interventions end preventable deaths in mothers, newborn babies, and stillbirths, and at what cost? Lancet 2014;384: 347-70.

4. Ronsmans C, Graham WJ, Lancet Maternal Survival Series steering group. Maternal mortality: who, when, where and why. Lancet 2006;368:1189-200.

5. Pearson L, Shoo R. Availability and use of emergency obstetric services: Kenya, Rwanda, Southern Sudan, and Uganda. Int J Gynaecol Obstet 2005;88:208-15.

6. van Lonkhuijzen L, Stekelenburg J, van Roosmalen J. Maternity waiting facilities for improving maternal and neonatal outcome in low-resource countries. Cochrane Database Syst Rev 2012;(10): CD006759.

7. Chaturvedi S, Randive B, Diwan V, et al. Quality of obstetric referral services in India's JSY cash transfer programmes for institutional births: a study from Madhya Pradesh province. PLOS ONE 2014;9: e96773.

8. Gorter AC, Ir P, Meessen B. Evidence Review: Results-based financing of maternal and newborn health care in low- and lower-middle-income countries. 2013. http://www.oecd.org/dac/ peer-reviews/Evidence-RBF-maternal-health.pdf 
9. Kruk ME, Hermosilla S, Larson E, et al. Bypassing primary care clinics for childbirth: a cross-sectional study in the Pwani region, United Republic of Tanzania. Bull World Health Organ 2014;92:246-53.

10. Long Q, Zhang Y, Raven J, et al. Giving birth at a health-care facility in rural China: is it affordable for the poor? Bull World Health Organ 2011;89:144-52.

11. Mselle LT, Moland KM, Mvungi A, et al. Why give birth in a health facility? Users' and providers' accounts of poor quality of birth care in Tanzania. BMC Health Serv Res 2013;13:174.

12. Lobis S, Mbaruku G, Kamwendo F, et al. Expected to deliver: alignment of regulation, training, and actual performance of emergency obstetric care providers in Malawi and Tanzania. Int J Gynaecol Obstet 2011;115:322-7.

13. Renfrew MJ, McFadden A, Bastos $\mathrm{MH}$, et al. Midwifery and quality care: findings from a new evidence-informed framework for maternal and newborn care. Lancet 2014;384:1129-45.

14. Crowther CA, Han S. Hospitalization and bed rest for multiple pregnancy. Cochrane Database Syst Rev 2010;(7):CD000110.

15. Sandall J, Soltani H, Gates S, et al. Midwife-led continuity models versus other models of care for childbearing women. Cochrane Database Syst Rev 2016;(4):Cd004667.

16. Hundley VA, Cruickshank FM, Lang GD, et al. Midwife managed delivery unit: a randomised controlled comparison with consultant led care. BMJ 1994;309:1400-4.

17. Cochrane Collaboration. Suggested risk of bias criteria for EPOC reviews. 2013. http://epoc.cochrane.org/sites/epoc.cochrane.org/ files/uploads/Suggested\%20risk\%20of\%20bias\%20criteria\%20for\% 20EPOC\%20reviews.pdf

18. Wells GA, Shea B, O'Connell D, et al. The Newcastle-Ottawa Scale (NOS) for assessing the quality of nonrandomised studies in meta-analyses. 2014. http://www.ohri.ca/programs/clinical_ epidemiology/oxford.asp

19. Hartling L, Milne A, Hamm MP, et al. Testing the Newcastle Ottawa Scale showed low reliability between individual reviewers. J Clin Epidemiol 2013;66:982-93.

20. Stang A. Critical evaluation of the Newcastle-Ottawa scale for the assessment of the quality of nonrandomized studies in meta-analyses. Eur J Epidemiol 2010;25:603-5.

21. Pratt JJ, Niedle PS, Vogel JP, et al. Alternative regimens of magnesium sulfate for treatment of preeclampsia and eclampsia: a systematic review of non-randomized studies. Acta Obstet Gynecol Scand 2015;95:144-56.

22. The PLOS Medicine Editors. Observational studies: Getting clear about transparency. PLoS Med 2014;11:e1001711.

23. Chambliss LR, Daly C, Medearis AL, et al. The role of selection bias in comparing caesarean birth rates between physician and midwifery management. Obstet Gynecol 1992;80:161-5.

24. Law YY, Lam KY. A randomized controlled trial comparing midwife-managed care and obstetrician-managed care for women assessed to be at low risk in the initial intrapartum period. J Obstet Gynaecol Res 1999;25:107-12.

25. Bernitz S, Rolland $\mathrm{R}$, Blix $\mathrm{E}$, et al. Is the operative delivery rate in low-risk women dependent on the level of birth care? A randomised controlled trial. BJOG 2011;118:1357-64.

26. Bernitz S, Asa E, Øian P. Economic evaluation of birth care in low-risk women. A comparison between a midwife-led birth unit and a standard obstetric unit within the same hospital in Norway. A randomised controlled trial. Midwifery 2012;28:591-9.

27. Hofmeyr GJ, Mancotywa T, Silwana-Kwadjo N, et al. Audit of a new model of birth care for women with low risk pregnancies in South Africa: the primary care onsite midwife-led birth unit (OMBU). BMC Pregnancy Childbirth 2014;12:417.

28. Homer C, Davis $G$, Petocz $P$, et al. Birth centre or labour ward? A comparison of the clinical outcomes of low-risk women in a NSW hospital. Aust J Adv Nurs 2000;18:8-12.

29. Rana TG, Rajopadhyaya R, Bajracharya B, et al. Comparison of midwifery-led and consultant-led maternity care for low risk deliveries in Nepal. Health Policy Plan 2003;18:330-7.

30. Eide BI, Nilsen AB, Rasmussen S. Births in two different units in the same clinic-a prospective study of healthy primiparous women. BMC Pregnancy Childbirth 2009;9:25.

31. Suzuki S, Hiraizumi Y, Satomi M, et al. Midwife-led care unit for "low risk" pregnant women in a Japanese hospital. J Matern Fetal Neonatal Med 2011;24:1046-50.

32. Suzuki S. Obstetric outcomes of low-risk labors at "Japanese tatami" mat delivery room: a preliminary study. J Perinat Med 2009;37:709-11.

33. Cheung NF, Mander R, Wang X, et al. Clinical outcomes of the first midwife-led normal birth unit in China: a retrospective cohort study. Midwifery 2011;27:582-7.

34. Cheung NF, Mander R, Wang X, et al. Views of Chinese women and health professionals about midwife-led care in China. Midwifery 2011;27:842-7.

35. Brocklehurst $P$, Hardy $P$, Hollowell J, et al, Birthplace in England Collaborative Group. Perinatal and maternal outcomes by planned place of birth for healthy women with low risk pregnancies: the birthplace in England national prospective cohort study. BMJ 2011;343:d7400.

36. Schroeder E, Petrou S, Patel N, et al. Cost effectiveness of alternative planned places of birth in woman at low risk of complications: evidence from the Birthplace in England national prospective cohort study. BMJ 2012;344:e2292.

37. The World Bank. Country and Lending Groups. 2015. http://data. worldbank.org/about/country-and-lending-groups

38. Saleem S, McClure EM, Goudar SS, et al. A prospective study of maternal, fetal and neonatal deaths in low- and middle-income countries. Bull World Health Organ 2014;92:605-12.

39. Souza JP, Gülmezoglu AM, Vogel J, et al. Moving beyond essential interventions for reduction of maternal mortality (the WHO Multicountry Survey on Maternal and Newborn Health): a cross-sectional study. Lancet 2013;381:1747-55.

40. Shah A, Fawole B, M'imunya JM, et al. Cesarean delivery outcomes from the WHO global survey on maternal and perinatal health in Africa. Int J Gynaecol Obstet 2009;107:191-7.

41. Tunçalp Ö, Were WM, Maclennan C, et al. Quality of care for pregnant women and newborns - the WHO vision. BJOG 2015;122:1045-9.

42. World Health Organization. WHO recommendations on health promotion interventions for maternal and newborn health 2015 recommendation 4 Maternity waiting homes. Geneva: World Health Organization, 2015.

43. Bernitz S, Øian P, Sandvik L, et al. Evaluation of satisfaction with care in a midwifery unit and an obstetric unit: a randomized controlled trial of low-risk women. BMC Pregnancy Childbirth 2016;16:143. 